\title{
EDITORIAL
}

\section{Introduction of the revised CENA Practice Standards for the emergency nursing specialist}

On behalf of the CENA board and the professional standards committee we are delighted to introduce readers to the revised CENA Practice Standards for the emergency nursing specialist.

The standards for the emergency nursing specialist identify areas of nursing practice and behaviours that articulate the unique characteristics of the speciality of emergency nursing.

The first edition of the Emergency Nurse Specialist Standards was developed to provide insight into and some broad practice guidelines for emergency nursing. The framework and research for these standards was undertaken by the standards sub-committee of the Australian Association of Emergency Nurses (AAEN), with input from many expert emergency nurses. The committee's initial efforts are contained within this document, which was transferred to the College of Emergency Nursing Australasia (CENA) in 2003 to continue with standards work and foster continued excellence in this area.

The intention of these standards is to reflect the practice standards for emergency nursing across Australasia and to provide the basis for discussion and debate within the emergency nursing profession. These practice standards will provide the foundation for further practice development and research in emergency nursing, and lead the way to improved benchmarking and best practice in emergency care.

As providers of emergency nursing services and education we encourage you to utilise these standards within your practice to identify and promote emergency nursing practices and expertise.

A full copy of the standards is available for download on our website at www.cena.org.au

Kelly-Ann Hahn, FCENA*

National Board Member, College of Emergency Nursing Australasia, Australia

*Tel.: +61 401383030 . E-mail address:keldaveandbuffy@gmail.com

20 February 2014 